\title{
Historical perspectives of The American Association for Thoracic Surgery: Isaac Alexander Bigger, Jr (1893-1955)
}

\author{
Patricia Nicolato, DO, ${ }^{\mathrm{a}}$ and Abe DeAnda, Jr, $\mathrm{MD}^{\mathrm{b}}$
}

Isaac A. Bigger, Jr, the 26th president of The American Association for Thoracic Surgery (Figure 1), was born in Bethel, South Carolina on June 25, 1893, to Isaac Alexander Bigger, a highly respected surgeon, and Mary Neel Johnston Bigger. He was 1 of 5 children, including 3 sisters and an older brother, who became a general practitioner. As was not uncommon for that era in the south, his earliest education was provided by a governess, Mary Brown, starting at the age of 7 , and during his homeschooling, he spent time in his father's office, known as the "doctor's shop," which was part of the family home. He often accompanied his father on house calls, and it is thought that these experiences with his father were the greatest influences in developing the very special bedside manner for which he was later known in his own practice.

Bigger's formal education began in 1909 at Erskine College in South Carolina. His first year was reportedly an unhappy one for him, and after the conclusion of the school year, he transferred to Davidson College in North Carolina, which was a hundred miles closer to home. He was a student at Davidson intermittently from 1910 to 1913 , although his studies were interrupted by severe bouts of bronchial asthma, a condition that would plague him for the rest of his life.

Bigger entered medical school at the University of Virginia in the fall of 1914. In his third year, he was elected to the Raven Society, honoring outstanding student performance and the expectation of future contributions, and was elected to the 13 society, honoring student leaders for unselfish service and unusual achievement. After graduation, Bigger stayed on for a 3-year surgical residency that included gynecology and orthopedics, followed by an appointment to the position of Assistant Professor of Surgery at the University of Virginia. While on the faculty, he was elected to Sigma Xi in 1927, a national honorary scientific society embracing all branches of science. ${ }^{1}$

After a half dozen years on the faculty at Virginia, Bigger accepted a position as Associate Professor of Surgery at Vanderbilt University. It was there that he became interested in the evolving field of thoracic surgery. He was strongly en-

\footnotetext{
From the Department of Cardiothoracic Surgery, ${ }^{a}$ Virginia Commonwealth University Medical Center, Richmond, Va; and the Department of Cardiothoracic

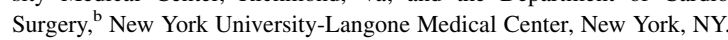
Received for publication Sept 10, 2010; accepted for publication Nov 14, 2010. Address for reprints: Patricia Nicolato, DO, Department of Surgery VCU Medical Center, 1200 E Broad St, West Hospital, 7th Floor, Richmond, VA 23112

(E-mail: patnico60@verizon.net).

J Thorac Cardiovasc Surg 2011;141:1098-100

$0022-5223 / \$ 36.00$

Copyright (C) 2011 by The American Association for Thoracic Surgery

doi:10.1016/j.jtcvs.2010.11.023
}

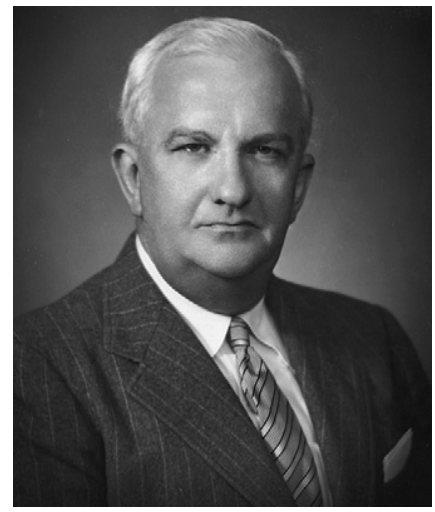

FIGURE 1. Isaac Alexander Bigger, Jr, MD. (Photo courtesy of the Special Collections and Archives, Tompkins-McCaw Library, Virginia Commonwealth University, Richmond, Va.)

couraged by his chairman, Dr Barney Brooks, to pursue this interest, and much of his early work was performed at the Davidson Tuberculosis Sanatorium. Although the opportunity at Vanderbilt was great, the lack of diversity in his immediate practice and the unkind environmental effect on his asthma helped influence his decision to accept an appointment at the Medical College of Virginia in 1930 as the Chairman of Surgery. Bigger was only 37 years old, and as reported in the Virginia Medical Monthly, he was the youngest full-time chairman in the country. ${ }^{1,2}$

Dr Bigger's legacy and commitment as a teacher is reflected in his early years in Richmond. During his first 10 years as chairman, Dr Bigger weathered strained relationships within his department as he began to make changes in the format of the residency program. The division of obstetrics and gynecology was within his department, and as time passed, he became more involved with the education of the gynecology residents. He felt that obstetricians and gynecologists needed to be well grounded in general surgery, and he became increasingly concerned as their training focused more and more on obstetrics rather than surgery. His concerns were well founded when in 1943 the Board of Obstetrics and Gynecology declined approval of graduate training for those trained on surgical services. He clarified his frustration in a letter dated May 15, 1950, to Dr William T Sanger, president of the Medical College of Virginia, summarizing the end of formal general surgery training for gynecologists. ${ }^{1}$

This is truly a remarkable situation, for, in the first place, gynecology is fundamentally a surgical specialty; in the second place, it is difficult to see how one could gain 


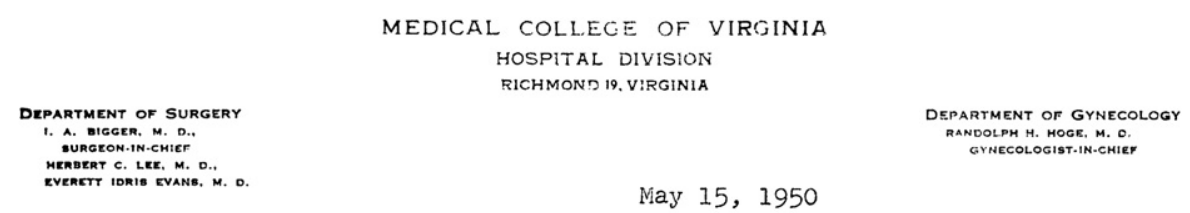

Dr. Wm. T. Sanger, President

Miedical College of Virginia

Richmond, Va.

Dear Doctor Sanger:

I agree with Dr. C. L. Riley that it is

most unfortunate that the service here is accredited

only for obstetrics. I had not been told this was

the case but I am not particularly surprised because

of certain very remarkable regulations of the American

Board of obstetrics and Gynecology. In one of their

recent pamphlets that Board stated that work done in

a gynecology department which was in any way associated

with the surgical department would not be acceptable

to that Board. Since our gynecology department is

connected with the surgical department their failure

to accredit the gynecological work here is readily

explained. This is truly a remarkable situation, for,

in the first place, gynecology is fundamentally a

surgical specialty; in the second place, 1t is difficult

to see how one could gain surgical experience on a

service which had no connection with surgery. It would

also seem absolutely essential that a gynecologist be

trained in abdominal surgery so that he would be in a

position to take care of the other surgical problems

encountered in connection with gynecological operations.

Yet, in spite of this, the American Board of Gynecology

and Obstetrics not only does not require that their

candidates have adequate surgical training, but actually

refuse to accept surgical training.

I am convinced that the gynecological service

at the Medical College of Virginia compares favorably with

those on any of the teaching services in this country. We

have offered to take the obstetrical residents on in

rotation, but the offer has not been accepted and the

reason it has not is they would not be given credit for it.

This strikes me as being most unfortunate situation and one

which the gynecologists and obstetricians have brought on

themselves.

$I A B / M$

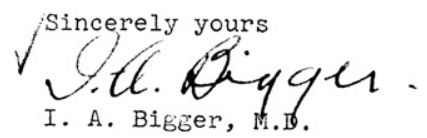

FIGURE 2. Letter from Dr Bigger to Dr Sanger. (Courtesy of the Special Collections and Archives, Tompkins-McCaw Library, Virginia Commonwealth University, Richmond, Va.)

surgical experience on a service which had no connection with surgery. It would also seem absolutely essential that a gynecologist be trained in abdominal surgery so that he would be in a position to take care of the other surgical problems encountered in connection with gynecological operations. Yet, in spite of this, the American Board of Gynecology and Obstetrics not only does not require that their candidates have adequate surgical training, but actually refuse to accept surgical training... This strikes me as being a most unfortunate situation and one which the gynecologists and obstetricians have brought on themselves [Figure 2].

Concomitant with his educational pursuits, Dr Bigger contributed extensively to the clinical development of the field of thoracic surgery. He compiled one of the largest series of cardiac trauma in the country, and of his 59 major publications, 14 were devoted to cardiac trauma, including diagnosis, pathophysiology, decision making, and surgical treatment. He was the second surgeon to perform a pericardiectomy, which was introduced by Edward Churchill of Boston in 1929 when Bigger was still at Vanderbilt. Bigger was one of the pioneers in pulmonary resection, decortication, and pneumonectomy and developed numerous procedures for congenital and acquired cardiothoracic conditions (arteriovenous fistula, esophageal atresia, and tracheoesophageal fistula) and general surgery conditions (bile duct reconstruction, thyroid surgery, and nerve blocks for hernia repair). In 1941, when the United States entered World War II, Bigger would have liked to pursue an active role in the military; however, his asthma 
precluded him from serving. He was able to contribute indirectly to the effort by consulting with the medical corps, including writing the Thoracic Surgery Manual in 1943, which was an important Army text used for the emergency treatment of battle wounds. ${ }^{1}$

On May 28, 1947, Dr Bigger delivered the Presidential Address at the 27th Annual Meeting of The American Association for Thoracic Surgery (AATS), in St Louis, Missouri. The speech was aimed at the general membership as a reflection on an impending and important milestone. After a year of review and study, under the leadership of the AATS, the membership were going to be presented with an AATS committee recommendation regarding the formation of a Board of Thoracic Surgery (later to be renamed the American Board of Thoracic Surgery) in affiliation with the American Board of Surgery. A previous exploration of this issue in 1936 had resulted in the feeling that such a board was not required. In an eloquent address that drew on quotations from Herodotus, Plato, Gross, Osler, and Halstead, Dr Bigger reviewed the pros and cons of specialization in medicine in general and in surgery in particular. He made the point that the invention of "special instruments and techniques" leads to the creation of modern specialties (eg, ophthalmoscope and ophthalmology, cystoscope and urology, and bronchoscope and thoracic surgery). The counterpoint was also made that the specialties, in turn, advance the field with further development of instruments and techniques as a consequence of their singular focus. He straddled the issue by supporting in principle the idea of specialization but arguing that such specialization should be rooted in a broad training regimen with preliminary focus on general clinical and medical sciences. ${ }^{1}$

At the time, specialty boards were moving toward specific requirements in length of training and breadth of clinical exposure, as well as limiting the scope of practice to the particular boards. Bigger was more of a proponent of diversity in training and felt that the trend toward specialization might prove dangerous, stating " ...the sclerosing effect of narrow training on the individual is serious but the training of succeeding generations of specialists by those who are constantly becoming more narrow in their outlook will almost inevitably lead to disaster." He ended his address with a plea to the AATS membership that "...may we not be taken in by the overenthusiastic advocates of arbitrary and rigid restrictions on practice." Bigger reiterated his opinion on overspecialization during his presidential address to the Southern Surgical Association in 1953, a speech that was delivered by Dr Deryl Hart because Dr Bigger was once again plagued by his persistent asthma complicated by chronic bronchial infections. ${ }^{1}$

With repeated hospitalizations starting in November 1953, Bigger's asthma became increasingly more difficult to treat. His last formal publication was the memoir of his associate, Dr Everett Evans, for the Southern Surgical Association, who died unexpectedly in January 1953. Shortly thereafter, Bigger suffered a fractured rib from coughing and massive gastric bleeding requiring several transfusions. In February 1954, he was transferred to New York Hospital for a fresh approach to treating his disease. Dr Harold Wolff, whose specialty was psychosomatic medicine, treated him for 16 days in acute care and then transferred him to the Payne-Whitney Psychiatric Division for 37 days. His health remained fragile, and on January 27, 1955, after a 3-week hospitalization, he died from pulmonary complications of his life-long asthma, chronic obstructive lung disease, and chronic bronchopulmonary infections. ${ }^{1}$

The memorials in honor of Dr Bigger were numerous, and all reiterated the same theme: he was a man who was genuinely great and good, a surgeon "too big for the city of Richmond" and yet dedicated to his southern roots, and someone whose consistent practice was to serve rather than be served. He was lauded for his tireless compassion to heal the sick and his insatiable desire to advance this surgical discipline. The Medical Society of Virginia adopted a resolution that said, in part: "He was the epitome of all the factors which compose the true image representing the dignity of man. No greater teacher ever lived.... Brilliant, honest, humble, inspiring, friendly, fatherly, charitable, judicious, careful, earnest, faithful - are some of the adjectives that fit this man among men." In short, Isaac Bigger was the quintessential role model for future generations of cardiothoracic surgeons and a proud reflection of the office of the president of the AATS.

\section{References}

1. Bosher LH Jr, Bigger IA Jr. A biographical sketch. 1986. Located at: Special Collections and Archives, Tompkins-McCaw Library, Virginia Commonwealth University, Richmond, Va.

2. Dabney V. Virginia Commonwealth University: a sesquicentennial history. Charlottesville, Va: University Press of Virginia; 1987. 